\title{
ATTAPULGITE CLAY OF THE VENTZIA BASIN, WESTERN MACEDONIA, GREECE, AS TEMPLATE IN SYNTHESIZING AMORPHOUS CARBON NANOTUBES
}

\author{
Koukakis P. ${ }^{1}$, Tsakiridis P. ${ }^{1}$, Ntziouni A. ${ }^{2}$, Kordatos K. ${ }^{2}$ and Perraki M. ${ }^{1}$ \\ ${ }^{1}$ National Technical University of Athens, School of Mining and Metallurgical Engineering, \\ 15780,Athens, Greece, koukakispanos@gmail.com,ptsakiri@central.ntua.gr, \\ maria@metal.ntua.gr \\ ${ }^{2}$ National Technical University of Athens, School of Chemical Engineering, 15780, Athens, \\ Greece,kordatos@central.ntua.gr,ntziouni@central.ntua.gr
}

\begin{abstract}
Attapulgite from the Ventzia Basin, Western Macedonia, Greece, was used as a template for preparing amorphous carbon nanotubes by vapor deposition polymerization (VDP) method and two different alcohols, furfuryl alcohol and ethylene glycol, as carbon source. The morphology and structure of the as-prepared carbon nanotubes were investigated by means of scanning electron microscopy and a transmission electron microscopy. X-ray diffraction and Raman spectroscopy were additionally employed. The amorphous nature of the carbon nanotubes has been confirmed by the XRD and the SAED pattern, as well as the Raman spectrum. No noticeable difference was observed in the morphology and structure of the as-prepared carbon nanotubes regarding the type of alcohol used as carbon source. However, a difference in the quantity of the produced carbon nanotubes was noticed, with the furfuryl alcohol, as carbon source, producing a larger amount of carbon nanotubes than the ethylene glycol.
\end{abstract}

Keywords: attapulgite, clay mineral, carbon nanotubes, Ventzia basin.

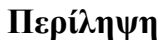

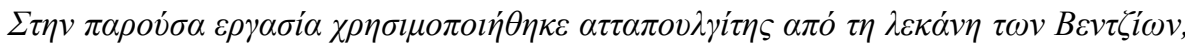

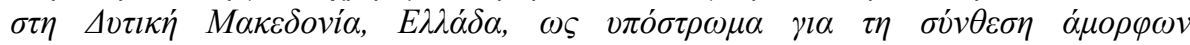

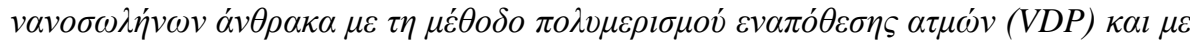

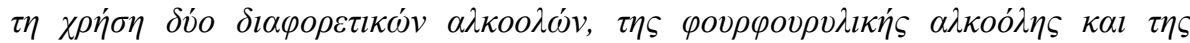

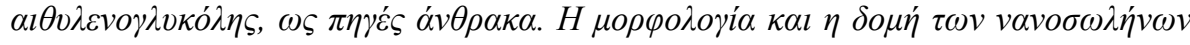

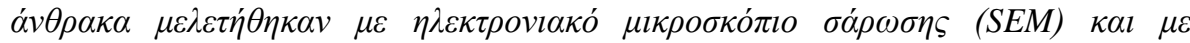

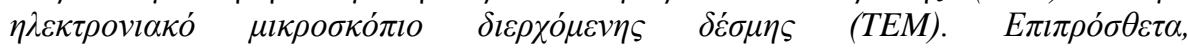

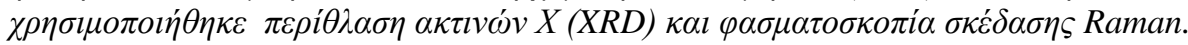

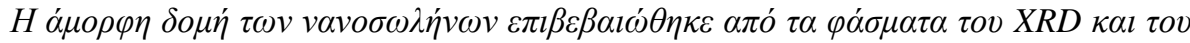

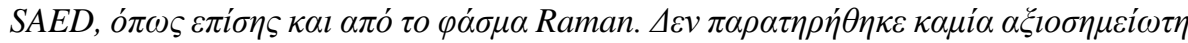

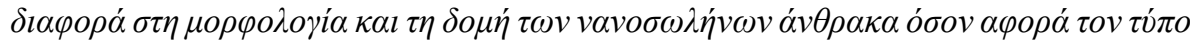

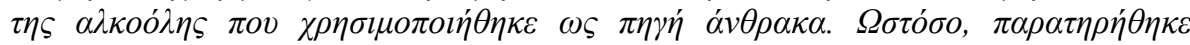

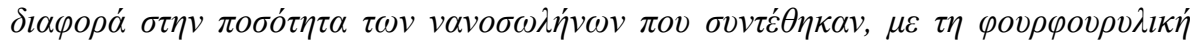

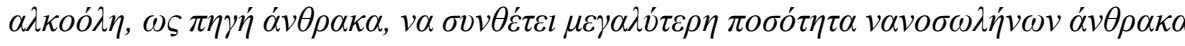
$\alpha \pi o ́$ $\tau \eta v \alpha \iota \theta v \lambda \varepsilon v o \gamma \lambda v \kappa o ́ \lambda \eta$.

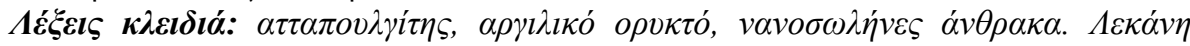
$B \varepsilon v \tau \zeta i \omega v$. 


\section{Introduction}

Attapulgite is a hydrated magnesium phyllosilicate $\left(\left[\mathrm{Mg}\left(\mathrm{Al}_{0.5-1} \mathrm{Fe}_{0-0.5}\right)\right] \mathrm{Si}_{4} \mathrm{O}_{10}(\mathrm{OH}) .4 \mathrm{H}_{2} \mathrm{O}\right)$ with magnesium partially replaced by aluminium or, to a lesser extent, iron (Bish and Guthrie, 1993), named after the U.S. town of Attapulgus, in southwest Georgia, where the mineral is abundant. The synonym palygorskite is derived from a deposit found at Palygorskaya on the Popovka River, Middle Urals, Russia. The attapulgite used in this paper, provided by GEOHELLAS S.A. is a commercial product and therefore the term attapulgite is used instead of the synonym palygorskite. Its structure consists of long double chains of silica tetrahedra which run parallel to the fiber axis. These chains are joined by magnesium and aluminum octahedra to produce strips similar in structures to the three-layer minerals. These three-layer strips are joined at the corners by Si-O-Si bonds into a structure resembling a checkerboard in cross-section, with free channels of about 3.7 by $6.0 \AA$ in cross-section running the length of the needles (Haden, 1963). These channels can collapse when attapulgite is dehydrated. The reason being the open-channel structure is stabilized by the water of composition which completes the edges of the octahedral strips (Preisinger, 1963). This collapse of the channels during dehydration is the probable cause of the abrupt decrease of the mineral's surface area from about 190 to $125 \mathrm{~m}^{2} / \mathrm{g}$ (Barrer and Mackenzie, 1954). Suitable acidification treatment or heat treatment of attapulgite could increase its surface area, pore volume and amount of active Si-OH bonds (Sun et al., 2012).

The important applied properties of attapulgite are a direct result of its needle-like structure. The attapulgite needle is commonly about $1 \mu \mathrm{m}$ in length and approximately $10 \mathrm{~nm}$ across. The properties of attapulgite are rarely determined by these tiny channels. The external surface of the needles and the arrangement of the needles in gross particles are of primary importance (Haden, 1963).

Attapulgite is being used in a wide variety of applications, both in heavy industry and in every-day life. Recent studies have shown that attapulgite can be used to synthesize carbon nanotubes, taking advantage of its fibrous morphology and diameter in nanoscale.

Recently, amorphous carbon nanotubes (ACNTs) have become a core research because of their low temperature synthesis process and large production yield. The walls of the ACNTs are composed of many carbon clusters featuring short-distance order and long-distance disorder. Amorphous carbon has both $\mathrm{sp}^{2}$ and $\mathrm{sp}^{3}$ bonding and contains parts of the properties of both diamond and graphite, which distinguish their properties from crystalline single-walled and multi-walled carbon nanotubes (Sun et al., 2012).

In this paper, a template synthesis technique was utilized to prepare ACNTs, using attapulgite as template and both furfuryl alcohol and ethylene glycol as carbon sources. This technique features the virtue of low cost and wide source of raw materials, its simple and easily reached process conditions, which may redeem some drawbacks of the commonly-used methods.

\section{Materials and Methods}

\subsection{Analytical Methods}

X-Ray Diffraction patterns were obtained with a Bruker D8 Focus diffractometer in a $\theta-\theta$ configuration employing $\mathrm{CuK} \alpha$ radiation $(\lambda=1.5406 \AA)$ with a fixed divergence slit size of $0.5^{\circ}$ and a rotating sample stage. The samples were scanned between 4 and $70^{\circ} 2 \theta$. The step size and time per step were set to $0.017^{\circ} 2 \theta$ and $80 \mathrm{~s}$, respectively. Scanning Electron Microscopy (SEM) was performed using a JEOL 6380LV-SEM equipped with an Oxford EDS-WDS. Transmission Electron Microscopy was performed with a JEOL 2100 HR-TEM at 200kV. A Renishaw's inVia-microRAMAN (532 nm excitation laser wavelength) was also employed to study the carbon products. 


\subsection{Raw Attapulgite}

Attapulgite from the Ventzia basin, Western Macedonia, Greece, was provided by GEOHELLAS S.A. which has exploited the attapulgite deposit since 2003.

\subsection{Synthesis Process}

The raw attapulgite was treated in $0.5 \mathrm{M} \mathrm{HCl}$ solution for 120 min under refluxing and magnetic stirring, then washed with distilled water to $\mathrm{pH}=7$ and dried at $105^{\circ} \mathrm{C}$ overnight.

The carbon nanotubes were synthesized through a vapor deposition polymerization (VDP) method. $2.0 \mathrm{~g}$ of acid-attapulgite were placed in a Teflon container, and t hen placed into a stainless steel autoclave. $3 \mathrm{~mL}$ of furfuryl alcohol were additionally added into the Teflon container. The high pressure autoclave was sealed and transferred into a homogeneous reactor at $180^{\circ} \mathrm{C}$ for $6 \mathrm{~h}$ (over the boiling point of furfuryl alcohol which is $170^{\circ} \mathrm{C}$ ). Thereafter, the furfuryl alcohol-attapulgite mixture was carbonized in a horizontal furnace under $\mathrm{Ar}_{2}$ atmosphere. The heating protocol rate was $60 \mathrm{~min}$ from room temperature to $300^{\circ} \mathrm{C}, 60 \mathrm{~min}$ from $300^{\circ} \mathrm{C}$ to $600^{\circ} \mathrm{C}$, held at $600^{\circ} \mathrm{C}$ for $2 \mathrm{~h}, 40 \mathrm{~min}$ from $600^{\circ} \mathrm{C}$ to $800^{\circ} \mathrm{C}$ and held at $800^{\circ} \mathrm{C}$ for $2 \mathrm{~h}$ to get the carbon-attapulgite hybrid material. Then, the carbonized black powders were stirred in HF (40 wt.\%) solution for $15 \mathrm{~h}$ in a fume cupboard at room temperature to dissolve the mineral template completely. Next, the resulting insoluble carbon based materials were filtered and washed by distilled water several times. Finally, the carbon based materials were treated with $\mathrm{HCl}(37 \mathrm{wt} . \%)$ solution under stirring at room temperature for $2 \mathrm{~h}$ to purify them, followed by filtering, washing with distilled water and drying in an oven at $105^{\circ} \mathrm{C}$ overnight (Sun et al., 2012).

The synthesis process using ethylene glycol as carbon source was similar apart from the following points: a) $5 \mathrm{~mL}$ of ethylene glycol were added in the Teflon container and b) the high pressure autoclave was transferred in a homogeneous reactor at $200^{\circ} \mathrm{C}$ (over the boiling point of ethylene glycol which is $197^{\circ} \mathrm{C}$ ) for $6 \mathrm{~h}$.

\section{Results and Discussion}

\subsection{Raw attapulgite}

XRD pattern of the raw attapulgite can be seen in Figure 1. It exhibits the characteristic attapulgite diffraction peaks at $\mathrm{d}=10.79 \AA, h k l(110), \mathrm{d}=4.4 \AA, h k l(040)$ and at $\mathrm{d}=3.5 \AA, h k l(400)$. The intense, sharp and symmetric peak at $\mathrm{d}=10.79 \AA$ indicates highly-crystalline pure attapulgite (Yan et al., 2013). The presence of quartz was verified in the studied samples by its typical diffraction peaks at $\mathrm{d}=\sim 3.34 \AA h k l(101)$ and $\mathrm{d}=\sim 4.25 \AA h k l(100)$.

Study by Scanning Electron Microscopy (SEM) showed a fibrous and sheet-like morphology for the attapulgite crystals whilst their length ranges from $1 \mu \mathrm{m}$ to $10 \mu \mathrm{m}$ (Figure 2). The EDS point analyses revealed an average attapulgite chemical formula of $\left(\mathrm{Si}_{7.72} \mathrm{Al}_{0.28}\right)\left(\mathrm{Al}_{0.77} \mathrm{Fe}\right.$ $\left.{ }_{0.91} \mathrm{Mg}_{2.52}\right)_{4.20} \mathrm{Ca}_{0.04} \mathrm{Na}_{0.02} \mathrm{~K}_{0.09} \mathrm{O}_{20}(\mathrm{OH})_{2}\left(\mathrm{OH}_{2}\right)_{4}$ (Kastritis et al., 2003).

Thermogravimetric (TG), Differential Thermal Gravimetric (DTG) and Differential Thermal analysis (DTA) curves of the raw attapulgite are given in Figure 3. As can be seen in the respective DTA curve attapulgite shows characteristic endothermic peaks. The first peak, at $120^{\circ} \mathrm{C}$, is due to the abortion of the surface absorbed water and part of the zeolitic water which exists in the canals of the attapulgite crystal. The second peak, at $300^{\circ} \mathrm{C}$, is due to the abortion of all the zeolitic water and part of the bound water. The third peak is wider, from $420^{\circ} \mathrm{C}$ to $600^{\circ} \mathrm{C}$, and indicates that all the water has been aborted and also the formation of anhydride. Around the temperature of $800-870^{\circ} \mathrm{C}$ the structure of the attapulgite completely collapses. The exothermic peak at $\sim 845^{\circ} \mathrm{C}$ is attributed to the formation of enstatite $\left(\mathrm{MgSiO}_{3}\right)$ (Che et al., 2011). 


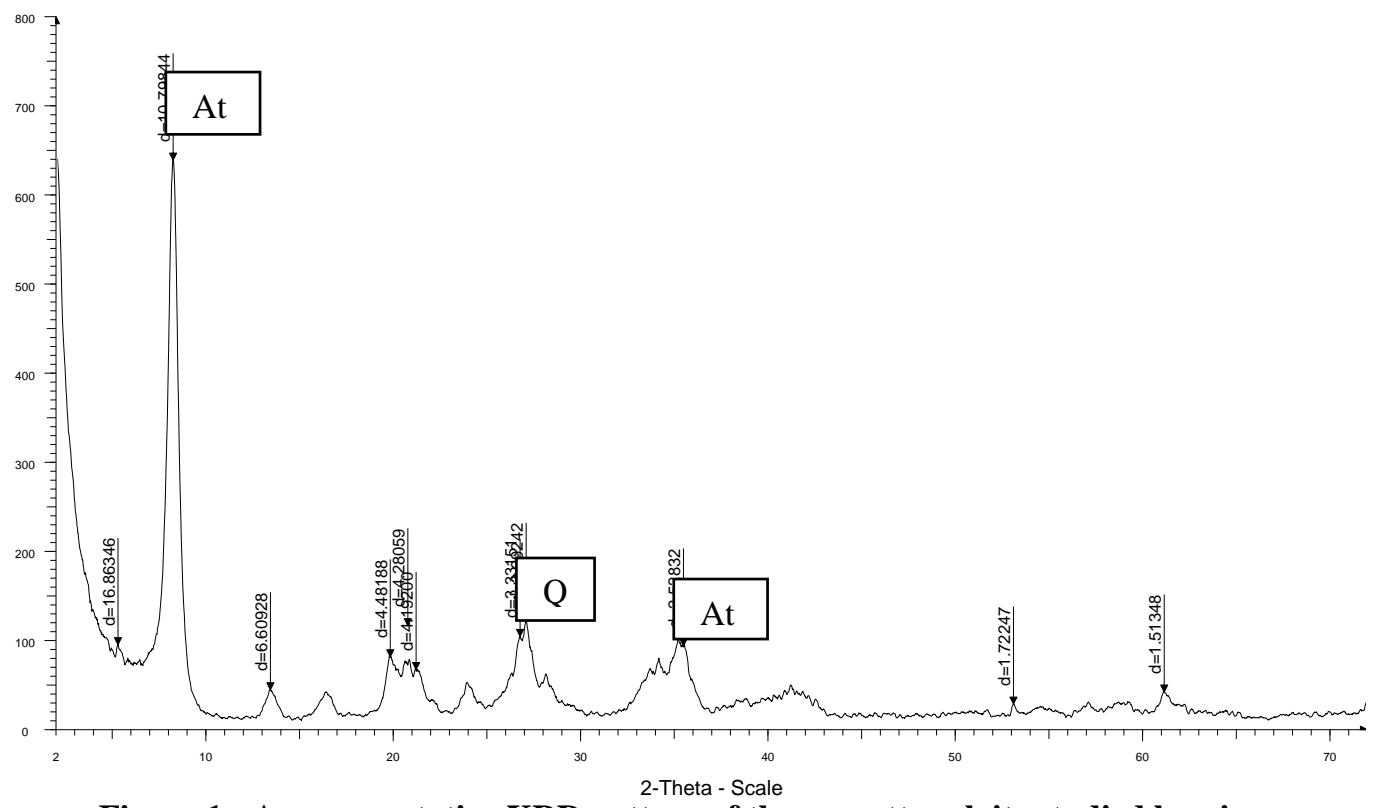

Figure 1 - A representative XRD pattern of the raw attapulgite studied herein.
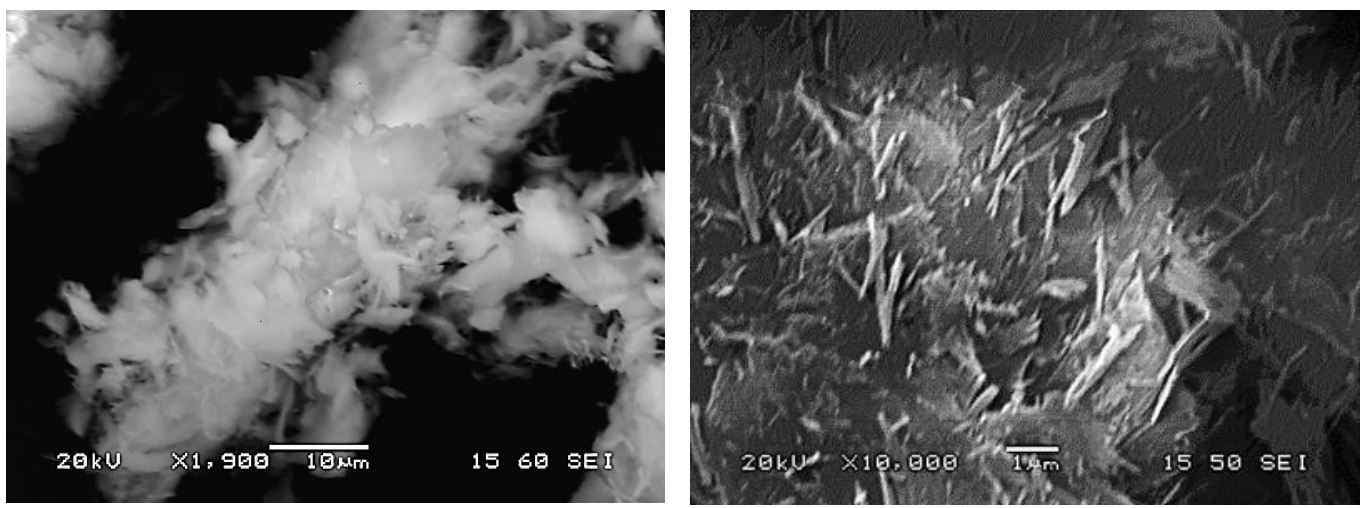

Figure 2 - SEM images of the attapulgite template.

\subsection{Products}

As can be seen, in the respective XRD patterns of the final product (Figure 4), the characteristic XRD peaks of the attapulgite have been disappeared, indicating that the mineral template has been completely removed. At around $2 \theta=26.3^{\circ}$ a very weak and wide peak is observed, possibly corresponding to the (002) plane of the carbon (Sun et al., 2012). The low intensity and width of the peak show that the as-prepared carbon nanotubes are amorphous.

In the SEM images of the as-prepared carbon nanotubes (Figure 5), it can be seen that the morphology is fibrous and sheet-like, similar to that of the attapulgite template, indicating that most of the carbon was deposited onto the surface of the template. In the case of the carbon nanotubes which were synthesized with ethylene glycol as carbon source, their morphology is more sheet-like. 


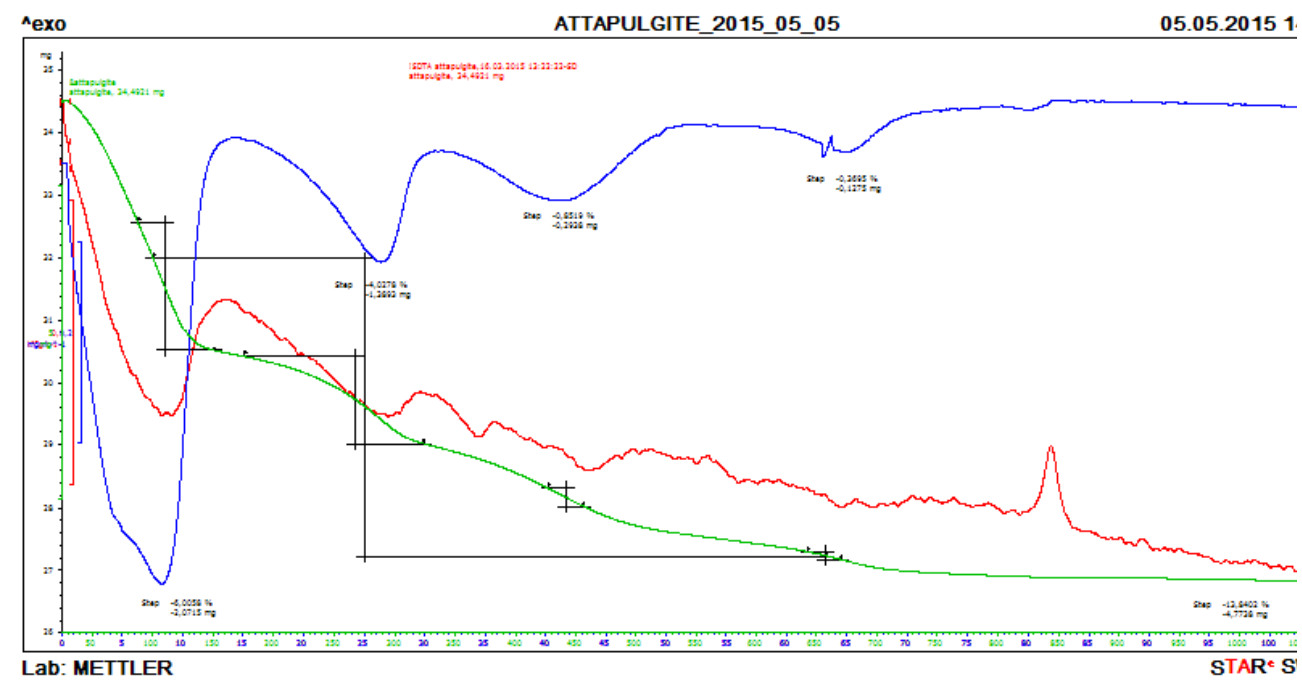

Figure 3 - TG/DTG/DTA curves of the studied raw attapulgite.

Intensity

(a.u.)

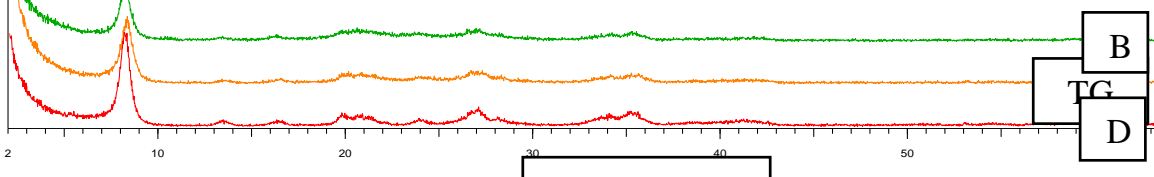

Figure 4 - XRD patterns of A) the as-prepared carbon nanotubes B) attapulgite treated with $0.5 \mathrm{M} \mathrm{HCl}$ for $2 \mathrm{~h} \mathrm{C}$ ) attapulgite treated with $0.5 \mathrm{M} \mathrm{HCl}$ for $1 \mathrm{~h}$ and D) raw attapulgite. 

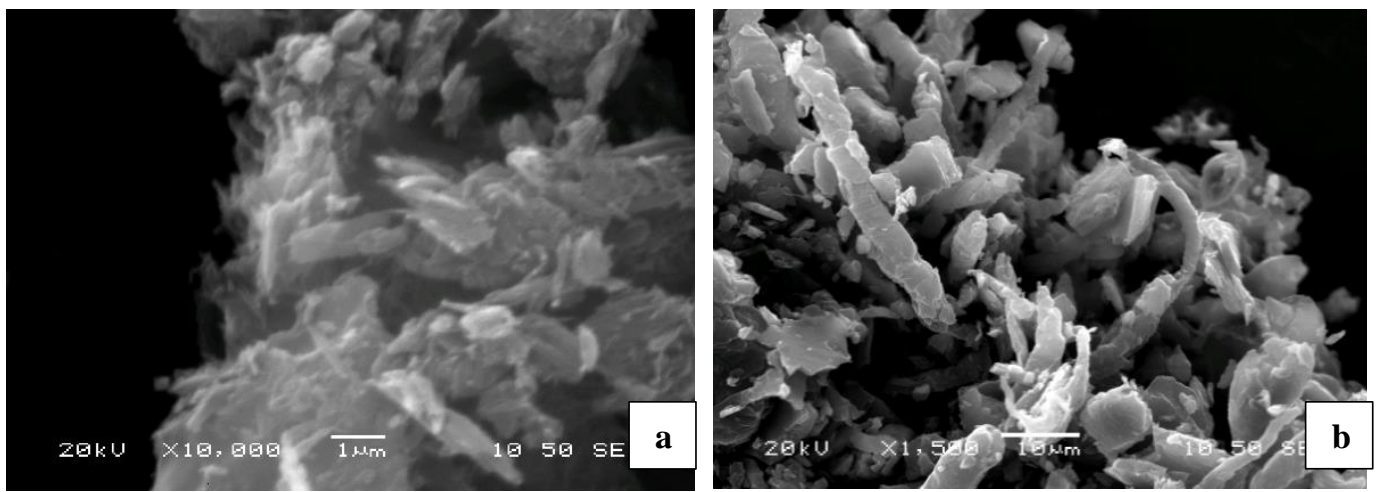

Figure 5 - SEM images of the as-prepared carbon nanotubes using a) furfuryl alcohol and b) ethylene glycol as carbon sources, respectively.
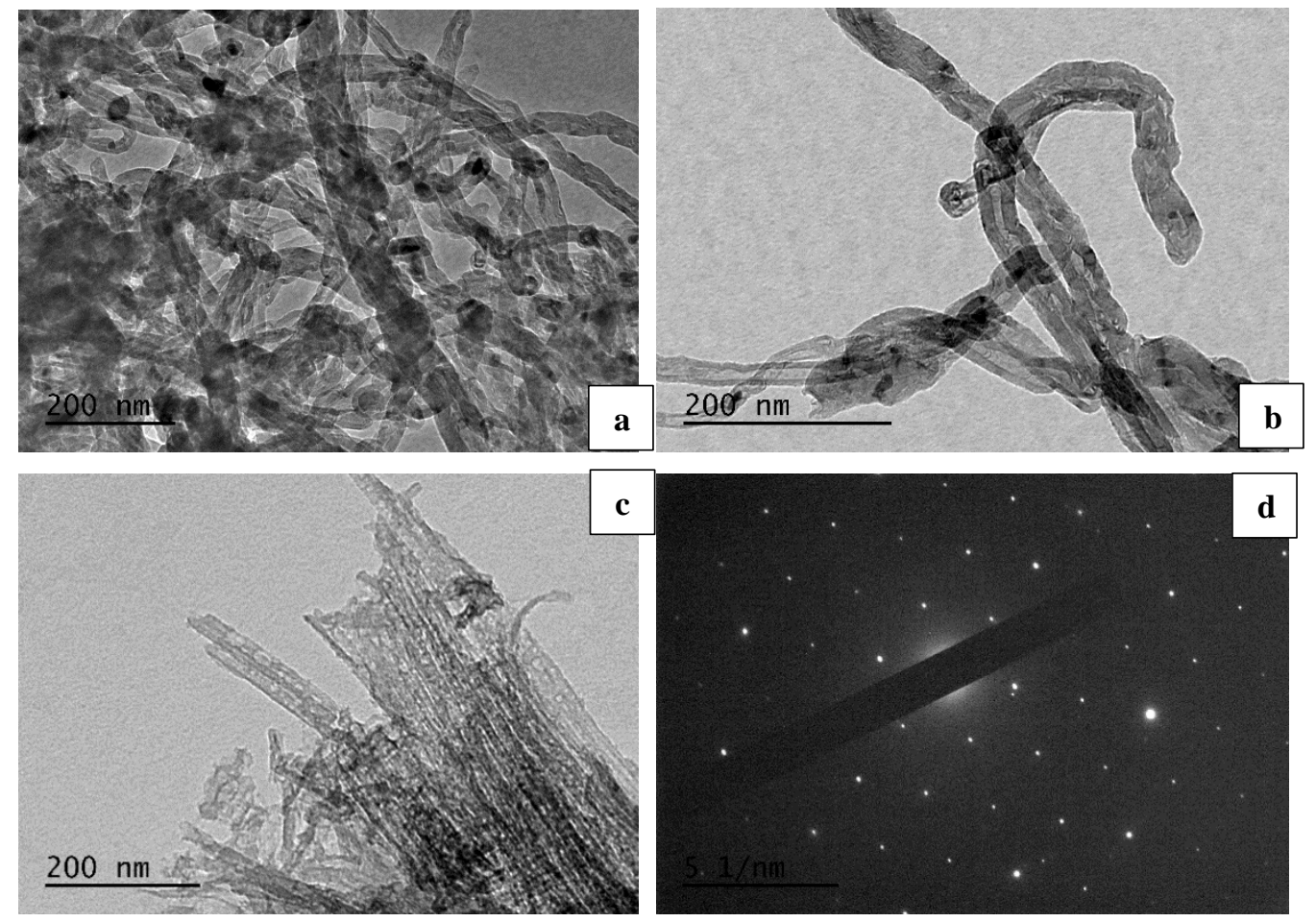

Figure 6 - TEM images (a,b,c) and SAED (d) pattern of the as-prepared carbon nanotubes using furfuryl alcohol as carbon source.

The morphology of the as-prepared carbon nanotubes was observed with Transmission Electron Microscopy (TEM) (Figures 6,7). The ACNTs are similar in shape and diameter to the attapulgite template. The Selected Area Electron Diffraction (SAED) pattern, in agreement with the XRD study, shows a featureless pattern which is indicative of the amorphous structure of the asprepared carbon nanotubes. 


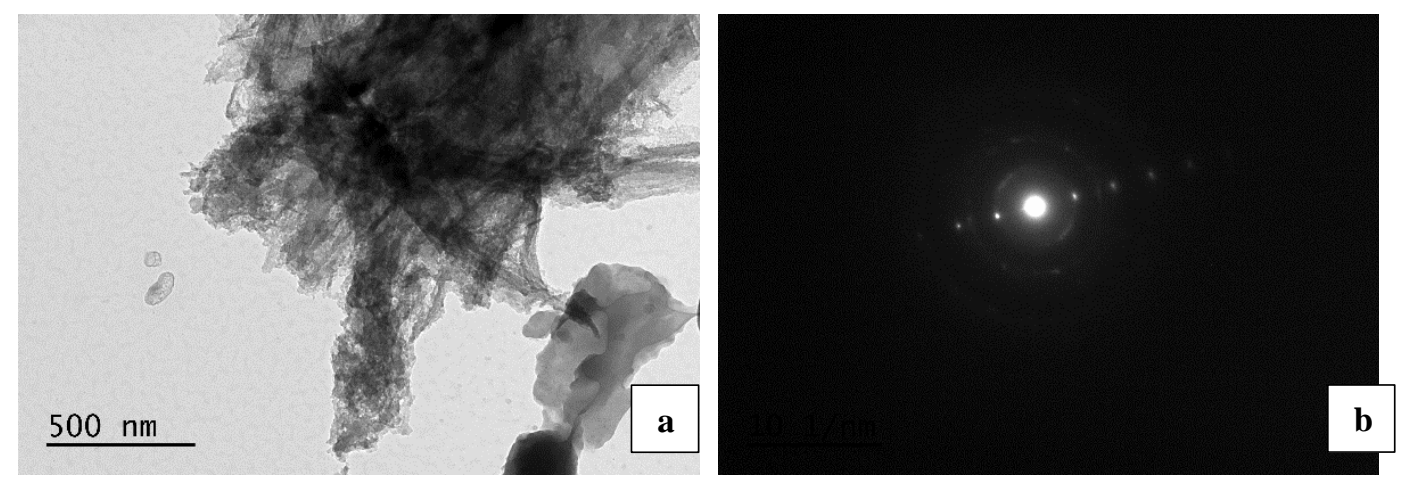

Figure 7 - TEM image (a) and SAED pattern (b) of the as-prepared carbon nanotubes usin g ethylene glycol as carbon source.

In Figure 8 a representative Raman spectrum of the carbon nanotubes is given. As can been seen the Raman features confirmed that the as-prepared carbon nanotubes are highly amorphous, as indicated by the two wide peaks at $1307 \mathrm{~cm}^{-1}$ and $1597 \mathrm{~cm}^{-1}$ (Chen, 2008).

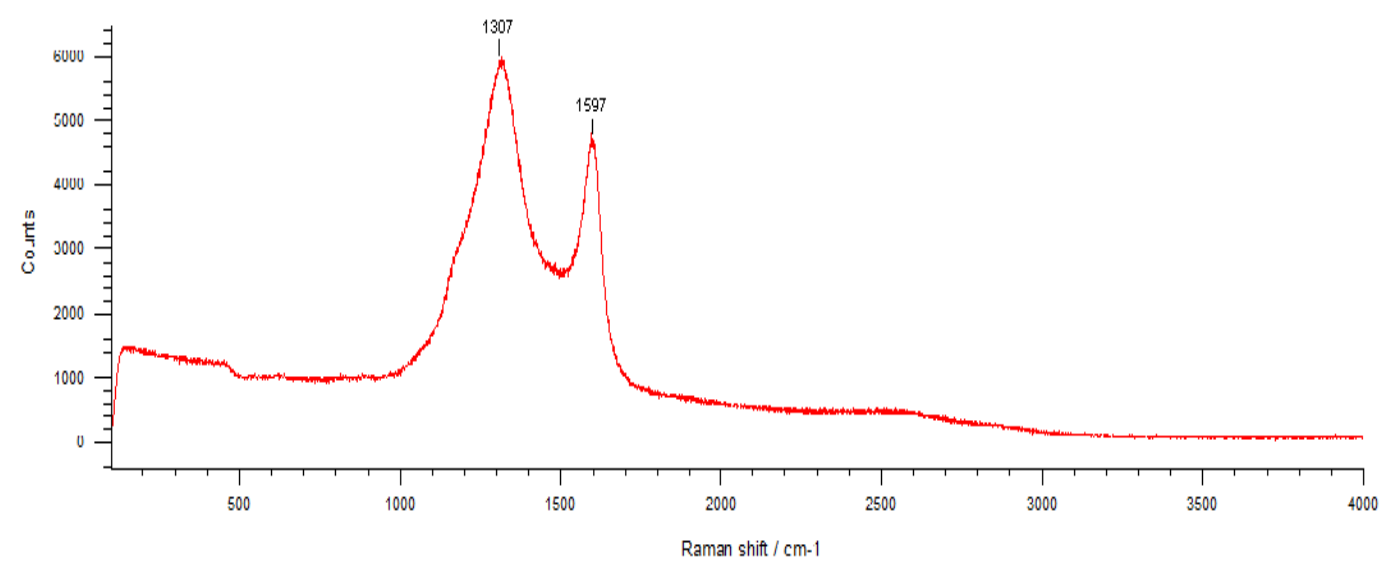

Figure 8 - Raman spectrum of the as-prepared carbon nanotubes.

\section{Conclusions}

Attapulgite from the Ventzia Basin, Western Macedonia, Greece, proved to be a suitable template for preparing amorphous carbon nanotubes by vapor deposition polymerization (VDP) method and furfuryl alcohol or ethylene glycol as carbon sources. The as-prepared carbon nanotubes were investigated by means of a scanning electron microscope and a transmission electron microscope to obtain information on their morphology and structure. X-ray diffraction and Raman spectroscopy were additionally employed. The amorphous nature of the carbon nanotubes has been confirmed by the XRD and the SAED pattern, as well as the Raman spectrum. No noticeable difference was observed in the morphology and structure of the as-prepared carbon nanotubes regarding the type of alcohol used as carbon source. However, a difference in the quantity was noticed as the furfuryl alcohol, as carbon source, produced a larger amount of carbon nanotubes than the ethylene glycol.

\section{Acknowledgments}

GEOHELLAS S.A. is thanked for providing the attapulgite sample. Vasilis Skliros is cordially thanked for his support in the Raman analysis of the samples. 


\section{References}

Barrer, R.M. and Mackenzie, N., 1954. Sorption by attapulgite, Part 1, Availability of intracrystalline channels, The Journal of Physical Chemistry, 58, 560-568.

Bish, D.L. and Guthrie, G.D.Jr., 1993. Mineralogy of clay and zeolite dusts (exclusive of 1:1 layer silicates). In: Guthrie, G.D.Jr and Mossman, B.T., eds., Reviews in Mineralogy, Health Effects of Mineral Dusts, Chelsea, MI, Book Crafters, 28, 139-184.

Che, C., Glotch, D.T., Bish, L.D., Michalski, R.J. and Xu, W., 2011. Spectroscopic study of the dehydration and/or dehydroxylation of phyllosilicate and zeolite minerals, Journal of Geophysical research, Planets, 116, Issue E5.

Chen, Y.-C., 2008. Raman spectroscopic studies on single-walled carbon nanotubes (SWNTs) and SWNT/Ag nanostructure, PHD thesis submitted to the University of Manchester, Faculty of Engineering and Physical Sciences, 205 pp.

Christidis, G.E., Katsiki, P., Pratikakis, A. and Kacandes, A., 2010. Rheological properties of palygorskite-smectite suspensions from the Ventzia basin, W. Macedonia, Greece, Bulletin of the geological Society of Greece, Proceedings of the $12^{\text {th }}$ International Congress, Patras, 2562-2569.

Haden, W.L.Jr., 1963. Attapulgite: properties and uses: in Clays and Clay Minerals, 1Oth Conf., Pergamon Press, New York, 284-290.

Kastritis, I.D., Kacandes, G.H. and Mposkos, E., 2003. The palygorskite and Mg-Fe smectite clay deposits of the Ventzia basin, western Macedonia, Greece, Mineral Exploration and Sustainable Development, Eliopoulos et al., eds., Millpress, Rotterdam, 891-894.

Preisinger, A., 1963. Sepiolite and related compounds: its stability and application, Clay and Clay Minerals, 10, 365-371.

Sun, L., Yan, C., Chen, Y., Wang, H. and Wang, Q., 2012. Preparation of amorphous carbon nanotubes using attapulgite as template and furfuryl alcohol as carbon source, Journal of Non-crystalline Solids, 358, 2723-2736.

Yan, W., Yuana, P., Chena, M., Wang, L. and Liu, D., 2013. Infrared spectroscopic evidence of a direct addition reaction between palygorskite and pyrometallitic dianhydride, Applied Surface Science, 265, 585-590. 